\title{
Lipid and DNA interaction with the triorganotin dimethylaminophenylazobenzoates studied by DSC and spectroscopy methods
}

\author{
Hanna Pruchnik ${ }^{1}$ (1) Teresa Kral $^{1,2} \cdot$ Martin Hof $^{2}$ \\ Received: 1 December 2017 / Accepted: 15 August 2018/Published online: 22 August 2018 \\ (c) The Author(s) 2018
}

\begin{abstract}
The aim of the study was to investigate and compare the interaction of tributyltin (TBTA) and triphenyltin (TPhTA) 2-[4 (dimethylamino)phenylazo]benzoates complexes with the lipid membrane and plasmid DNA. Both TBTA and TPhTA belong to the group of promising anticancer agents. Differential scanning calorimetry method was employed to examine the heat signal associated with phase transitions of liposomes formed from dipalmitoylphosphatidylcholine (DPPC) or DPPC/cholesterol and modified with TBTA and TPhTA. The investigated compounds influence the thermotropic parameters of the DPPC and DPPC/cholesterol lipid bilayer in a slightly different way: Although the temperature of the main phase transition of the DPPC remains almost unaffected, the addition of TPhTA can abolish sub- and pre-transition when added in sufficiently high concentrations. At the same time, the addition of the TBTA practically does not change the sub-transition and only slightly influences the pre-transition. The effect of organotin compounds on plasmid DNA was investigated using single-molecule florescence technique and time-correlated single-photon counting fluorescence correlation spectroscopy. Influence of TBTA and TPhTA on DNA resulted only in fractional conformation change which did not lead to the tightly packed conformation however, analysis of the diffusion times indicates that TPhTA interacts with DNA in a different mode than TBTA.
\end{abstract}

Keywords Triorganotin complexes $\cdot$ Phase transition $\cdot$ DSC $\cdot$ Lipid bilayer $\cdot$ DNA $\cdot$ TCSPC-FCS

\section{Introduction}

In recent years, the organotin(IV) complexes were synthesized and tested as possible anticancer agents. Many of them exhibited interesting activity against specific cancer cell lines, and moreover, many of them turned out to be more effective than traditional heavy-metal anticancer drugs [1-12]. Therefore, investigation of new compounds with potential antitumor activity and side effects as low as possible has attracted considerable attention. Numerous

Hanna Pruchnik

hanna.pruchnik@upwr.edu.pl

1 Department of Physics and Biophysics, Wrocław University of Environmental and Life Sciences, Norwida 25,

50-375 Wrocław, Poland

2 J. Heyrovsky Institute of Physical Chemistry of the ASCR, v.v.i., Dolejškova 2155/3, 18223 Prague 8, Czech Republic studies have shown that antitumor activity of organotin(IV) depends on the properties of the group coordinated to the tin atom and most frequently diminishes in the order: $n$ $\mathrm{Bu}>\mathrm{Ph}>n$-Pr $>\mathrm{Et}>\mathrm{Me}$. The most active antitumor agents are diorganotin and triorganotin compounds. In this paper, we compare the interaction of two compounds: tributyltin (TBTA) and triphenyltin (TPhTA) 2-[4 (dimethylamino)phenylazo]benzoates-TTA (Fig. 1) with membrane lipids and DNA. Previous in vitro studies show that investigated compounds have cytotoxic activity against human cancer cell lines A549 (lung adenocarcinoma) and HCV29T (bladder cancer cells). Both TBTA and TPhTA are very active against A549 cells. Also in relation to HCV29T human cell line, they are more active than cis-platinum [13, 14]. The mechanism of biological activity of organotin compounds is not yet totally clear. Toxicity of organometallic compounds may be accounted to their interaction with lipid components of biological membrane which may result in changed structure and 
Fig. 1 Chemical structure of TTA (TBTA and TPhT) complexes
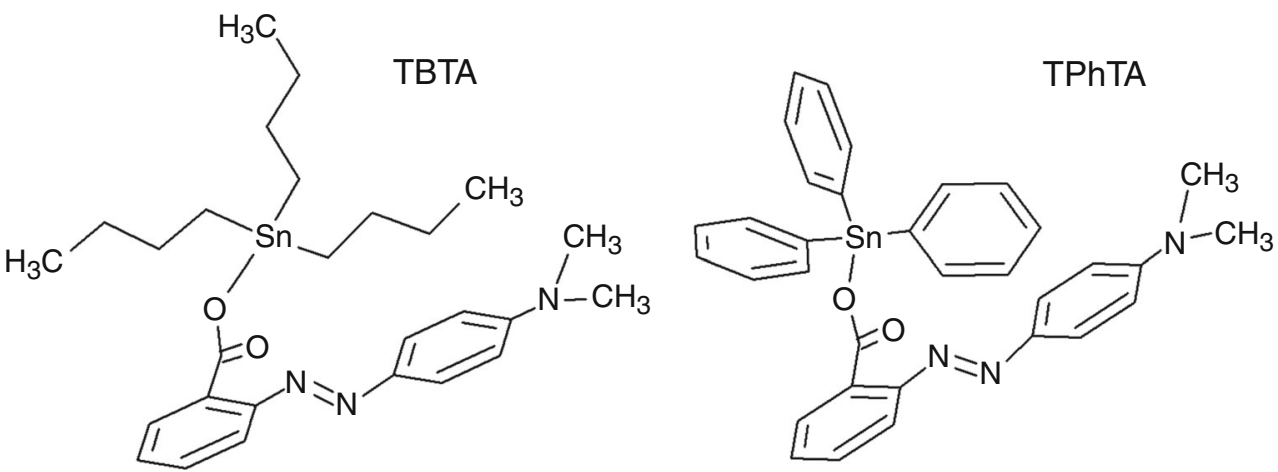

function of the membrane, because the phospholipid bilayers are the fundamental constituent of cell membrane. It is well documented that the composition of the membrane lipids and their structure play an important role in the functioning and conformation of the embedded membrane proteins. The membrane lipids can also regulate the distribution and localization of peripheral proteins and then participate in numerous important cellular activities such as cell adhesion and cell signaling. Increasing evidences have shown that drug molecules directly or indirectly interact with the membrane which, in turn, lead to changes in a drug's properties, pharmacological activity and bioavailability. Unfavorable drug interaction with lipid membrane can have adverse effects, such as drug resistance. Some authors proposed that DNA may be the probable target for the cytotoxic activity of organotin complex [15-19]. The ability of these complexes to bind with DNA depends on the coordination number and the nature of groups bonded to the central tin atom. Di- $n$-butyltin and tri- $n$-butyltin chloride, are known to induce apoptosis in rat thymocytes, inhibit DNA synthesis and increase RNA synthesis $[4,20]$.

The aim of this paper is to present the study of interactions of the investigated complexes with lipid membranes and plasmid DNA, in particular-their ability to compact DNA and their influence on the membrane structure and thermotropic phase behavior. The effect of TBTA and TPhTA on the lipid bilayer phase transition was examined by differential scanning calorimetry (DSC). DSC is a useful method for studying the nature of biological systems such as lipids or proteins [21, 22]. Thermal parameters that were monitored include the temperature at the pre-transition $\left(T_{\mathrm{p}}\right)$ and the main transition peak $\left(T_{\mathrm{m}}\right)$, the half-width $\left(\Delta T_{1 / 2}\right)$ and change of the enthalpy $(\Delta H)$ of the main transition. To understand the molecular interaction of TBTA and TPhTA compounds with plasmid DNA, we used a single-molecule florescence technique, timecorrelated single-photon counting fluorescence correlation spectroscopy (TCSPC-FCS).

\section{Materials and methods}

\section{Chemicals}

The complexes $\quad\left[\mathrm{Sn}\left(\mathrm{C}_{6} \mathrm{H}_{5}\right)_{3}\left\{\mathrm{OOC}-2-\mathrm{C}_{6} \mathrm{H}_{4} \mathrm{~N}=\mathrm{NC}_{6} \mathrm{H}_{4}\right.\right.$ $\left.\left.\mathrm{N}\left(\mathrm{CH}_{3}\right)_{2}-4\right\}\right]$-TBTA and $\left[\mathrm{Sn}\left(\mathrm{C}_{4} \mathrm{H}_{9}-n\right)_{3}\left\{\mathrm{OOCC}_{6} \mathrm{H}_{4}\right.\right.$ $\left.\left.\mathrm{N}=\mathrm{NC}_{6} \mathrm{H}_{4} \mathrm{~N}\left(\mathrm{CH}_{3}\right)_{2}-4\right\}\right]$ - TPhTA were prepared in accordance with procedures described in the literature [13, 14]. The most probable structure of this compound is as shown in Fig. 1.

The 1,2-dipalmitoyl-sn-glycero-3-phosphatidylcholine (DPPC) lipid and cholesterol were purchased from SigmaAldrich, Steinheim, Germany.

\section{Differential scanning calorimetry}

Samples for DSC were prepared from multilamellar liposomes (MLV) of pure phosphatidylcholine (DPPC) and of DPPC with cholesterol (5 and $10 \mathrm{~mol} \%$ ). The lipids (cholesterol) and compounds were dissolved in chloroform and in ethanol, respectively. Chloroform and ethanol were very carefully evaporated to dryness under nitrogen, and thin film was formed on the flask wall, after which distilled water was added. The lipid film was dispersed by agitating the flask on a vortex mixer to give a milky suspension of liposomes at a temperature above the main phase transition of phosphatidylcholine. Final lipids' concentration in the samples was $25 \mathrm{mg} \mathrm{cm}^{-3}$. The prepared MLV of lecithin and lecithin with the compounds added were encapsulated in $40 \mu \mathrm{L}$ volumes and incubated for 4 days at $4{ }^{\circ} \mathrm{C}$. The measurements were made with the Mettler Toledo Thermal Analysis System D.S.C. $821^{\mathrm{e}}$ operated at a heating rate of $2{ }^{\circ} \mathrm{C} \min ^{-1}$ from 5 to $55{ }^{\circ} \mathrm{C}$ of DPPC and DPPC/chol. Thermal cycles were repeated three times, and the experimental error in temperature and thermal response were $\pm 0.2{ }^{\circ} \mathrm{C}$ and $\pm 5 \%$, respectively. Data analysis was done using original software provided by Mettler Toledo in order to determine the temperature of the sub-transition $\left(T_{\mathrm{s}}\right)$, pre-transition $\left(T_{\mathrm{p}}\right)$, main transition $\left(T_{\mathrm{m}}\right)$, the main 
half-width transition $\left(\Delta T_{1 / 2}\right)$ and the transition enthalpy $\left(\Delta H_{\mathrm{m}}\right)$ of the main phase transition.

\section{Time-correlated single-photon counting fluorescence correlation spectroscopy (TCSPC-FCS)}

In order to evaluate the biological behavior of TPhTA and TBTA, the compounds were initially dissolved in ETOH $(1 \mathrm{mM})$. Mixing of such solutions with the aqueous DNA solutions used in the studies never exceeded 5\% ETOH (v/ v) in the final solution, which was needed due to low aqueous solubility of compounds. The DNA plasmid was labeled by PicoGreen ${ }^{\circledR}\left(C_{\text {Pico }} / C_{\text {DNA bp }}=0.02\right)$ [23]. The $\mathrm{pH} \quad \beta A \mathrm{pr}-1-\mathrm{Neo}$ plasmid (10 kbp and contour length $3.4 \mu \mathrm{m}$ ) was a generous gift from the laboratory of Prof. Maciej Ugorski (Department of Biochemistry and Molecular Biology, Wrocław University of Environmental and Life Sciences Wroclaw, Poland). After labeling DNA molecules mixed with appropriate amount of TPhTA or TBTA and left overnight, they were ready for measurements. All studies were performed at room temperature $\left(25^{\circ} \mathrm{C}\right)$. Time-correlated single-photon counting fluorescence correlation spectroscopy (TCSPC-FCS) was used to analyze the interaction with plasmid DNA of TPhTA and TBTA complexes [24].

\section{Results and discussion}

\section{Interaction with lipids: influence on thermotropic phase behavior of DPPC and DPPC/cholesterol}

Phospholipids show thermotropic and lyotropic phase behavior. These lipids form hydrated biomolecular lamellar phases, in which the lipid molecules are packed either in a quasicrystalline two-dimensional lattice (gel phase) or remain in a lamellar arrangement but show higher twodimensional fluidity. Transition between these phases can be induced by temperature changes, changes in hydration or binding of cations. This transition is called a main (major) phase transition, from lamellar gel phase to liquid (fluid) phase, but pure DPPC shows a more complicated phase behavior: There is also so-called intermediate $\mathrm{P}_{\beta^{\prime}}$ phase, in which the surface of the bilayer is distorted by a periodic ripple, and $\mathrm{L}_{\beta^{\prime}}$ phase in which the molecules are tilted at an angle of about $30^{\circ}$ relative to bilayer normal. The change from $L_{\beta^{\prime}}$ to $P_{\beta^{\prime}}$ has been termed pre-transition. When DPPC dispersion is cooled for extended periods of time at temperatures just above $0{ }^{\circ} \mathrm{C}$, another lamellar phase is formed, the so-called $\mathrm{L}_{\mathrm{c}}$ phase, in which the chains are highly ordered in a orthorhombic lattice [25]. The $\mathrm{L}_{\mathrm{c}}$ to $\mathrm{L}_{\beta^{\prime}}$ transition has been termed sub-transition. The sub- transition corresponds to a bilayer "crystal" $\rightarrow$ bilayer $\mathrm{L}_{\beta^{\prime}}$ gel structural rearrangement accompanied by a decrease in the lateral hydrocarbon chain interactions [26-30]. Thus, with the help of DSC, the heat signal associated with the three transitions: from $\mathrm{L}_{\mathrm{c}}$ to $\mathrm{L}_{\beta^{\prime}}$, from $\mathrm{L}_{\beta^{\prime}}$ to $\mathrm{P}_{\beta^{\prime}}$ and from $\mathrm{P}_{\beta^{\prime}}$ to $\mathrm{L}_{\alpha}$ (the main phase transition) was examined (Figs. 2, 3).

In the absence of the compound, three characteristic endothermic peaks are visible referring to the sub-transition $\left(T_{\mathrm{s}}=22.4 \pm 0.2{ }^{\circ} \mathrm{C}\right)$, the pre-transition $\left(T_{\mathrm{p}}=35.8 \pm\right.$ $\left.0.2{ }^{\circ} \mathrm{C}\right)$ and the main transition $\left(T_{\mathrm{m}}=41.4 \pm 0.2{ }^{\circ} \mathrm{C}\right)$, respectively. The presence of TBTA only slightly reduces cooperativity of the main phase transition, increasing its half-width from $0.5 \pm 0.2$ to $0.9 \pm 0.2{ }^{\circ} \mathrm{C}$ for the increasing concentration of the compound. Below the molar ratio of 0.067 , TBTA practically does not affect the main phase transition temperature (Table 1). At higher concentrations, it only slightly lowers the temperature: $T_{\mathrm{m}}=40.5 \pm 0.2^{\circ} \mathrm{C} \quad$ for $\quad n_{\mathrm{TBTA}} / n_{\mathrm{DPPC}}=0.2 \quad\left(\Delta T_{\mathrm{m}}\right.$ $=0.9 \pm 0.2^{\circ} \mathrm{C}$ ). Additionally, at higher concentrations, the main phase transition peak splits into two components: the first corresponding to the $T_{\mathrm{m}}$ of pure DPPC and the second slightly shifted toward lower temperatures (Fig. 2).

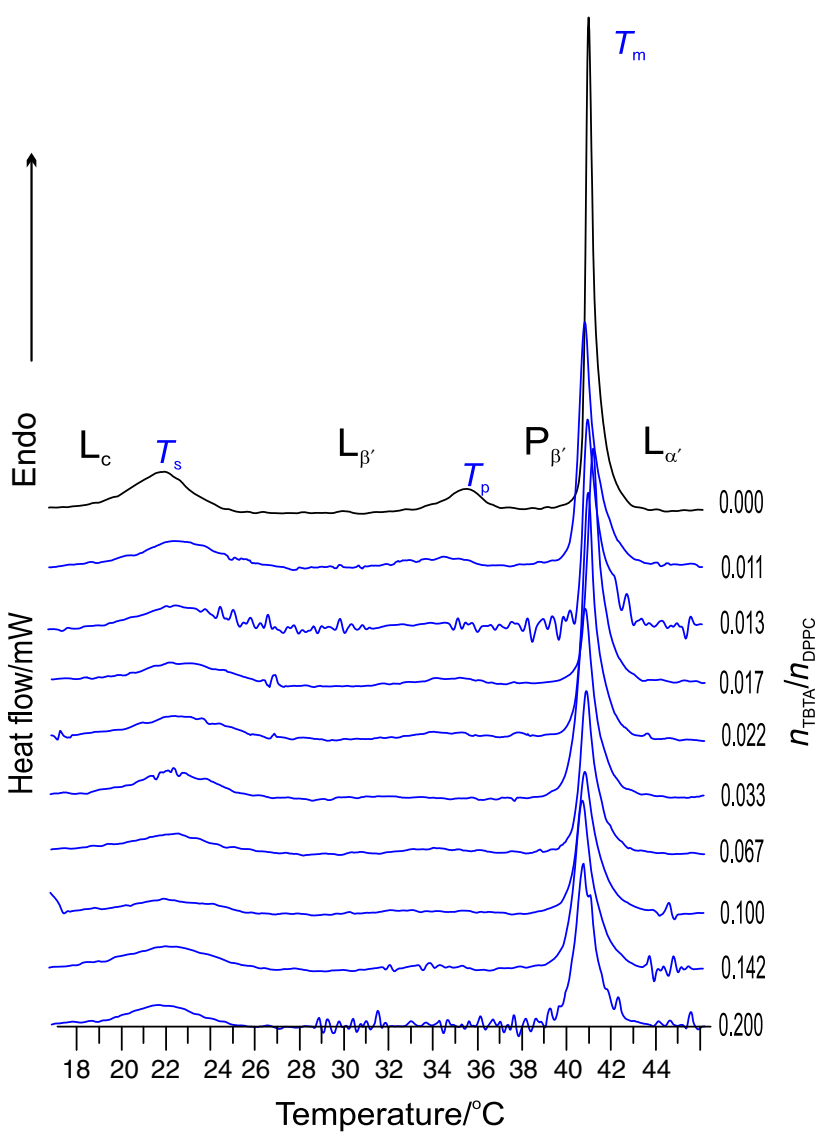

Fig. 2 DSC transition curves of MLVs with DPPC modified with the TBTA 


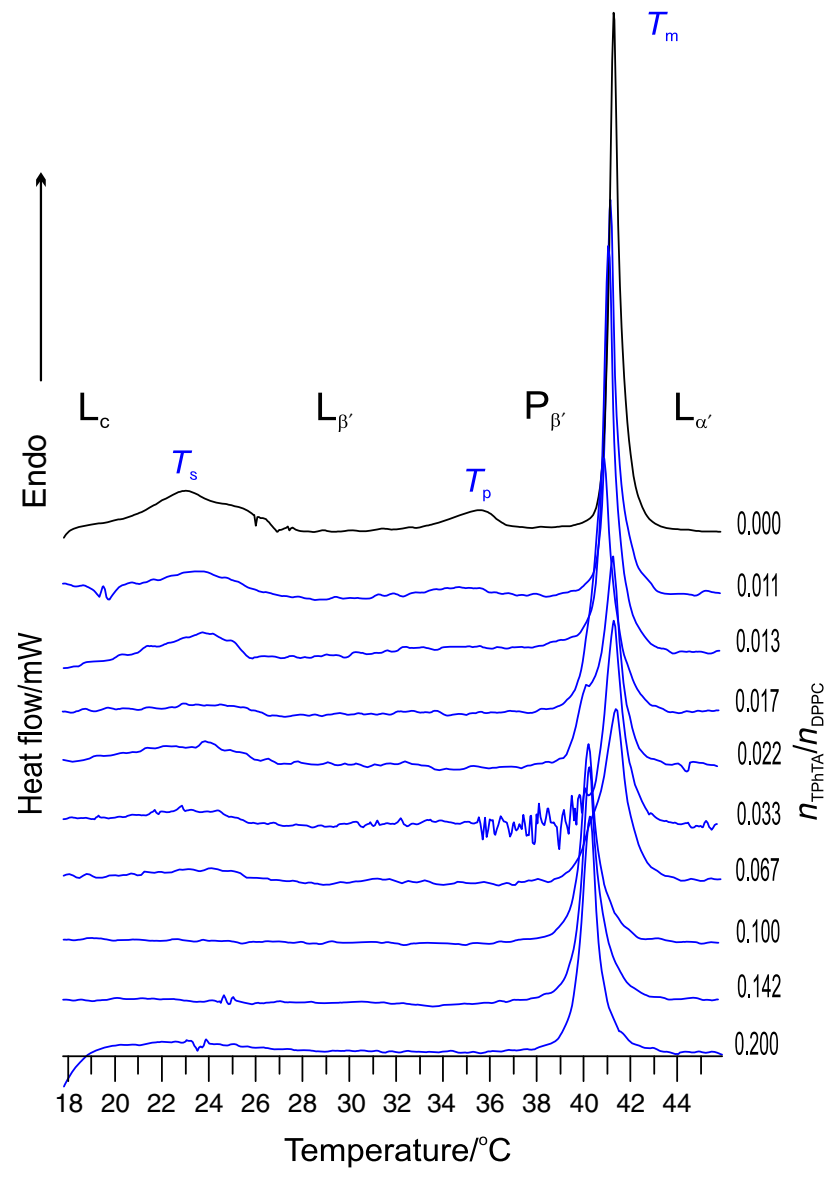

Fig. 3 DSC transition curves of MLVs with DPPC modified with the TPhTA

These results may indicate the coexistence of various phases with different compositions. Changes to the heat flow might therefore be associated with formation.
Changes to the heat flow might therefore be associated with formation of different domains consisting of different TBTA-DPPC compositions and consequently-with different $T_{\mathrm{m}}$ values. The TBTA does not eliminate the subtransition, whereas the pre-transition is abolished for higher concentrations (Fig. 2). TPhTA, in comparison with TBTA, induces slightly larger change in thermotropic parameters. TPhTA decreases the $T_{\mathrm{m}}\left(\Delta T_{\mathrm{m}}=1.5 \pm 0.2{ }^{\circ} \mathrm{C}\right.$ for $n_{\mathrm{TPhTA}} / n_{\mathrm{DPPC}}=0.2$ ) and reduces the cooperativity of the main phase transition $\left(0.5 \pm 0.2{ }^{\circ} \mathrm{C} \leq \Delta T_{1 / 2}\right.$ $\leq 1.3 \pm 0.2{ }^{\circ} \mathrm{C}$ ) (Table 1). The increase in TPhTA concentration causes the disappearance of both the sub-transition and pre-transition (Fig. 3). Both TBTA and TPhTA do not cause significant changes in the enthalpy of the main transition of DPPC. In conclusion, the differences between the effects of tested compounds on the thermotropic parameters of the membrane are particularly evident when the DPPC bilayer is in the gel phase. It is unknown that the formation of the ripple phase is dependent on the head group of lipids. This fact indicates that the interaction with the solvent may play a role in the formation of such phases. Since the pre-transition is a result of changes in acyl chain packing, its perturbation and/or vanishing indicates that TTA probably influences the structure of the lipid bilayer. On the other hand, compounds that incorporate into the polar-nonpolar region of the lipid bilayer abolish the DPPC pre-transition even at low concentrations [31-33]. Thus, we concluded that both TTA compounds interact with membrane phospholipids and may be localized rather on the surface of lipid bilayers and interact with the DPPC head group. However, the TPhTA induces slightly more changes in the thermotropic membrane parameters $\left(T_{\mathrm{s}}, T_{\mathrm{p}}\right.$, $\left.T_{\mathrm{m}}, \Delta T_{1 / 2}\right)$ than TBTA.
Table 1 Temperature values of the sub-transition $\left(T_{\mathrm{s}}\right)$, pretransition $\left(T_{\mathrm{p}}\right)$, the main $\left(T_{\mathrm{m}}\right)$ phase transition and peak halfwidth $\left(\Delta T_{1 / 2}\right)$ of the main phase transition for DPPC liposomes, in the absence and in the presence of TTA compounds

\begin{tabular}{|c|c|c|c|c|c|c|c|c|}
\hline \multirow[t]{2}{*}{$n_{\mathrm{TTA}} / n_{\mathrm{DPPC}}$} & \multicolumn{4}{|l|}{ TBTA } & \multicolumn{4}{|c|}{ TPhTA } \\
\hline & $T_{\mathrm{m}} /{ }^{\circ} \mathrm{C}$ & $\Delta T_{1 / 2} /{ }^{\circ} \mathrm{C}$ & $T_{\mathrm{p}} /{ }^{\circ} \mathrm{C}$ & $T_{\mathrm{s}} /{ }^{\circ} \mathrm{C}$ & $T_{\mathrm{m}} /{ }^{\circ} \mathrm{C}$ & $\Delta T_{1 / 2} /{ }^{\circ} \mathrm{C}$ & $T_{\mathrm{p}} /{ }^{\circ} \mathrm{C}$ & $T_{\mathrm{s}} /{ }^{\circ} \mathrm{C}$ \\
\hline 0.000 & 41.4 & 0.5 & 35.8 & 22.4 & 41.4 & 0.5 & 35.8 & 22.3 \\
\hline 0.011 & 41.2 & 0.5 & 34.8 & 22.2 & 41.2 & 0.6 & 34.8 & 22.4 \\
\hline 0.013 & 41.2 & 0.6 & 35.2 & 22.3 & 41.2 & 0.6 & - & 22.4 \\
\hline 0.017 & 41.6 & 0.7 & 34.7 & 22.5 & 41.6 & 1.0 & - & 22.7 \\
\hline 0.022 & 41.2 & 0.7 & 34.9 & 22.9 & 41.4 & 1.0 & - & 22.5 \\
\hline 0.033 & 41.2 & 0.8 & 34.4 & 22.9 & 41.4 & 0.9 & - & 23.1 \\
\hline 0.067 & 40.9 & 0.8 & 34.2 & 22.4 & 41.4 & 1.3 & - & 22.6 \\
\hline 0.010 & 41.1 & 0.9 & 33.4 & 22.5 & 40.3 & 0.9 & - & - \\
\hline 0.142 & 40.4 & 0.9 & 33.4 & 22.7 & 40.1 & 0.9 & - & - \\
\hline 0.200 & 40.5 & 0.9 & - & 22.5 & 39.9 & 0.8 & - & - \\
\hline
\end{tabular}

Accuracy of the temperature measurement is $\pm 0.2{ }^{\circ} \mathrm{C}$. Lack of the value means that the transition was not observed 
The differences in the effect of test compounds on the phase transition of the model membrane are more evident when we add cholesterol to the lipid bilayer. The most important function of the cholesterol is perhaps its ability to modulate the physicochemical properties of cellular membranes. In the membrane, the cholesterol interacts with membrane phospholipid and influences their behavior. Cholesterol induces an "intermediate state" in phospholipid molecules with which it interacts, increasing the fluidity of the hydrocarbon chains in temperatures below the $T_{\mathrm{m}}$ and decreasing the fluidity in temperatures above it. The content of $5 \mathrm{~mol} \%$ of cholesterol in the membrane formed from DPPC eliminates pre-transition. Incorporation of increasing levels of cholesterol broadens and eventually eliminates altogether the cooperative gel/liquid phase transition of the lipid bilayer. When the amount of cholesterol in the membrane formed from phosphatidylcholine ranges from 5 to $20 \mathrm{~mol} \%$, two phases with different cholesterol contents are formed [34-38]. In our experiments, two different concentrations of cholesterol were used: $5 \mathrm{~mol} \%$ and $10 \mathrm{~mol} \%$, for which sharp main transition occurs (Figs. 4, 5).

In the case of MLVs and the presence of cholesterol, we observed greater change of $T_{\mathrm{m}}$ and $\Delta T_{1 / 2}$ than for pure DPPC. It is interesting that TBTA does not abolish the subtransition of DPPC/cholesterol and its presence slightly increases (for $5 \mathrm{~mol} \%$ ) the cooperativeness of the main phase transition (Fig. 4a). These results suggest that TBTA most probably interacts with the surface of the bilayer. TPhT decreases $T_{\mathrm{m}}$ and increases the $\Delta T_{1 / 2}$. Additionally, in the presence of this compound, the main phase transition not only broadens but also becomes very asymmetrical (Figs. 4b, 5). In model membrane with 5 and $10 \mathrm{~mol} \%$ cholesterol content, cholesterol-rich and cholesterol-poor lipid domains are formed and the main phase transition stops being cooperative. The presence of TTA compounds,
Fig. 4 DSC transition curves of MLVs with DPPC/chol 5 mol\% modified with the TBTA (a) and TPhTA (b)

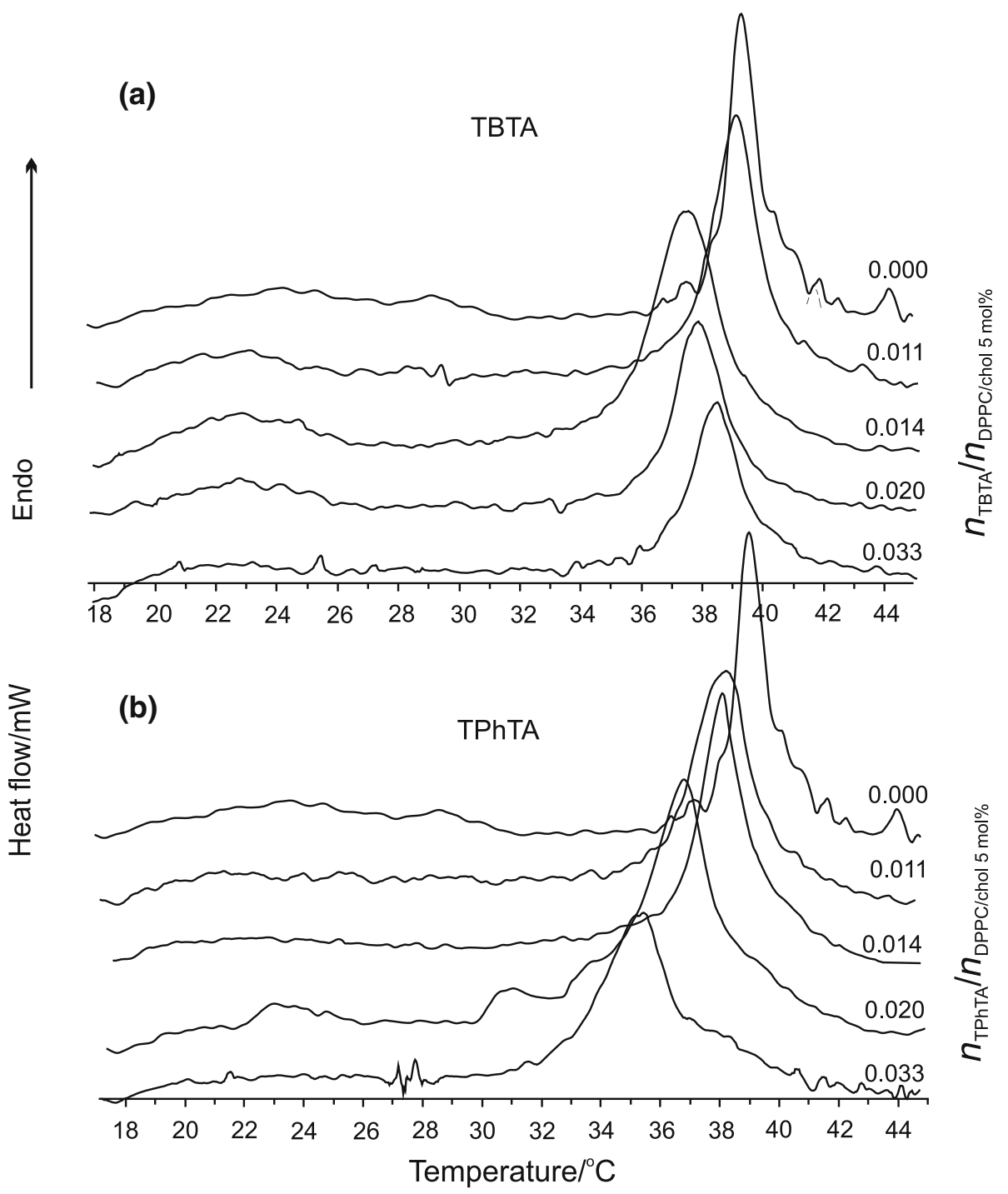



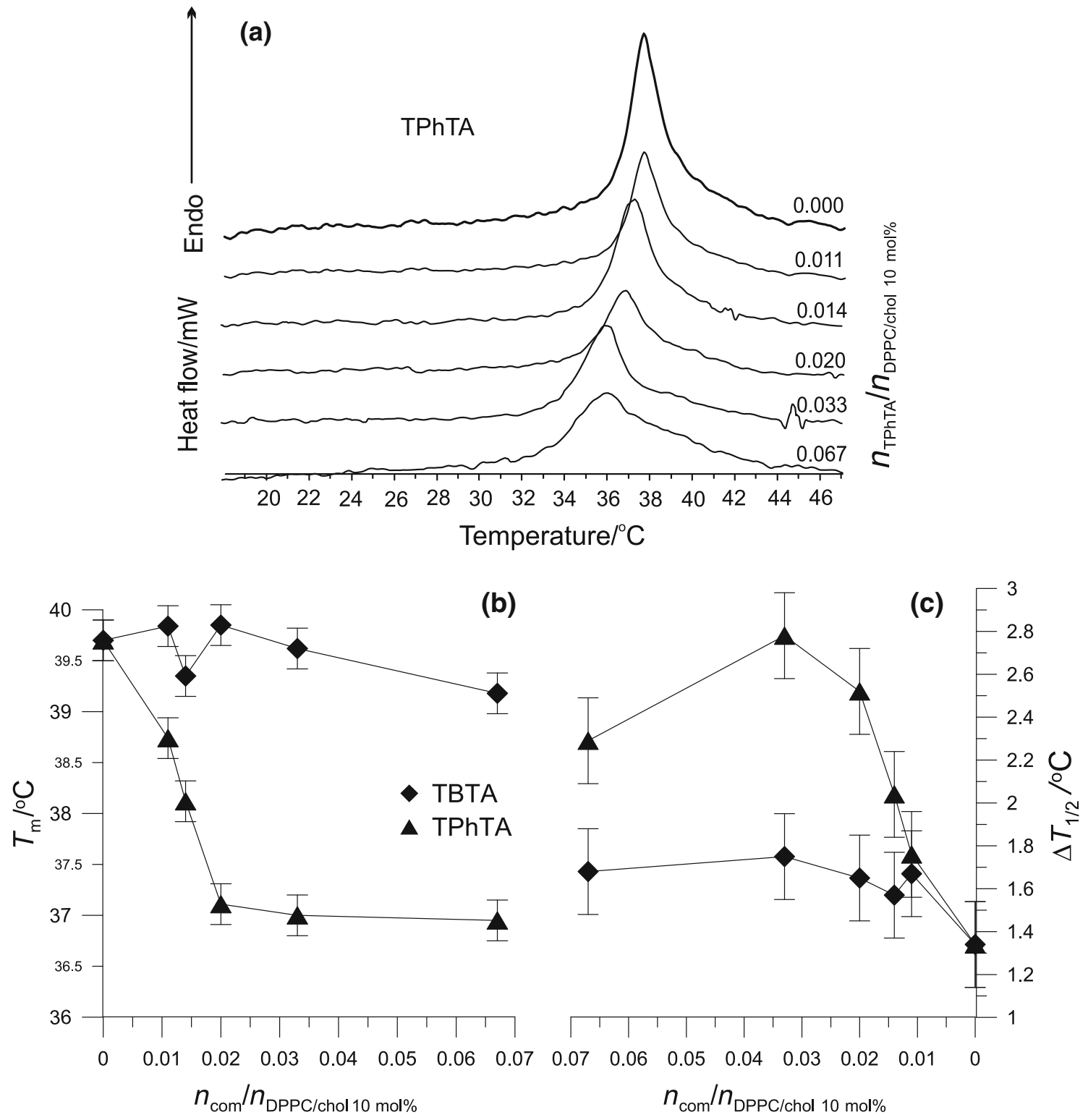

Fig. 5 DSC transition curves of MLVs with DPPC/chol $10 \mathrm{~mol} \%$ modified with the TPhTA (a), main phase transition temperatures $\left(T_{\mathrm{m}}\right)(\mathbf{b})$ and half-width $\left(\Delta T_{1 / 2}\right)$ peak $(\mathbf{c})$ as a function of TTA concentration

especially TPhTA, makes the lipid/cholesterol membrane more fluid. The increase in the asymmetry of the main DPPC/cholesterol phase permeation may result from the fact that compounds unevenly locate in cholesterol-rich and cholesterol-poor domains.

\section{Interaction with DNA: plasmid DNA-binding studies}

The TCSPC-FCS method was used to estimate how ethanoic solutions of the TBTA and TPhTA compounds and ethanol itself affect DNA conformation changes. Experiments were performed over concentrations, expressed here as $C_{\text {comp }} / C_{\text {DNA bp }}$ ratio, varying from 0 up to 5 molecules of the TBTA and TPhTA per one DNA base pair. Figure $6 a-d$ show the diffusion time, particle number, lifetime and the count rate dependence on the $C_{\text {comp }} / C_{\text {DNA bp }}$ ratio.

The diffusion time of DNA decreases monotonically both with increased percentage of the ethanol and increasing concentration of the ethanoic solution of the TBTA compound (Fig. 6a). As can be seen, with the increase in TPhTA concentration, after initial decrease for the $C_{\text {comp }} / C_{\text {DNA bp }}<0.2$, the progressive increase was observed up to $C_{\text {comp }} / C_{\text {DNA bp }}=1$, and then for $C_{\text {comp }} /$ $C_{\text {DNA bp }}>1$, a progressive decrease in the diffusion time was observed.

There is evidence that TPhTA interacted with DNA in a different mode than TBTA. An estimated diffusion time of 
Fig. 6 Diffusion time (a), particle number (b), lifetime

(c) and count rate

(d) dependence on $C_{\text {comp }} /$ $C_{\text {DNAbp }}$ ratio and ethanol volume fraction, EtOH Soln. (\%). The $\mathrm{pH} \beta$ Apr-1-Neo plasmid (10 kbp and contour length $3.4 \mu \mathrm{m})$ was labeled with PicoGreen ${ }^{\circledR}\left(C_{\text {Pico }}\right.$ '

$C_{\text {DNA bp }}=0.02$ )
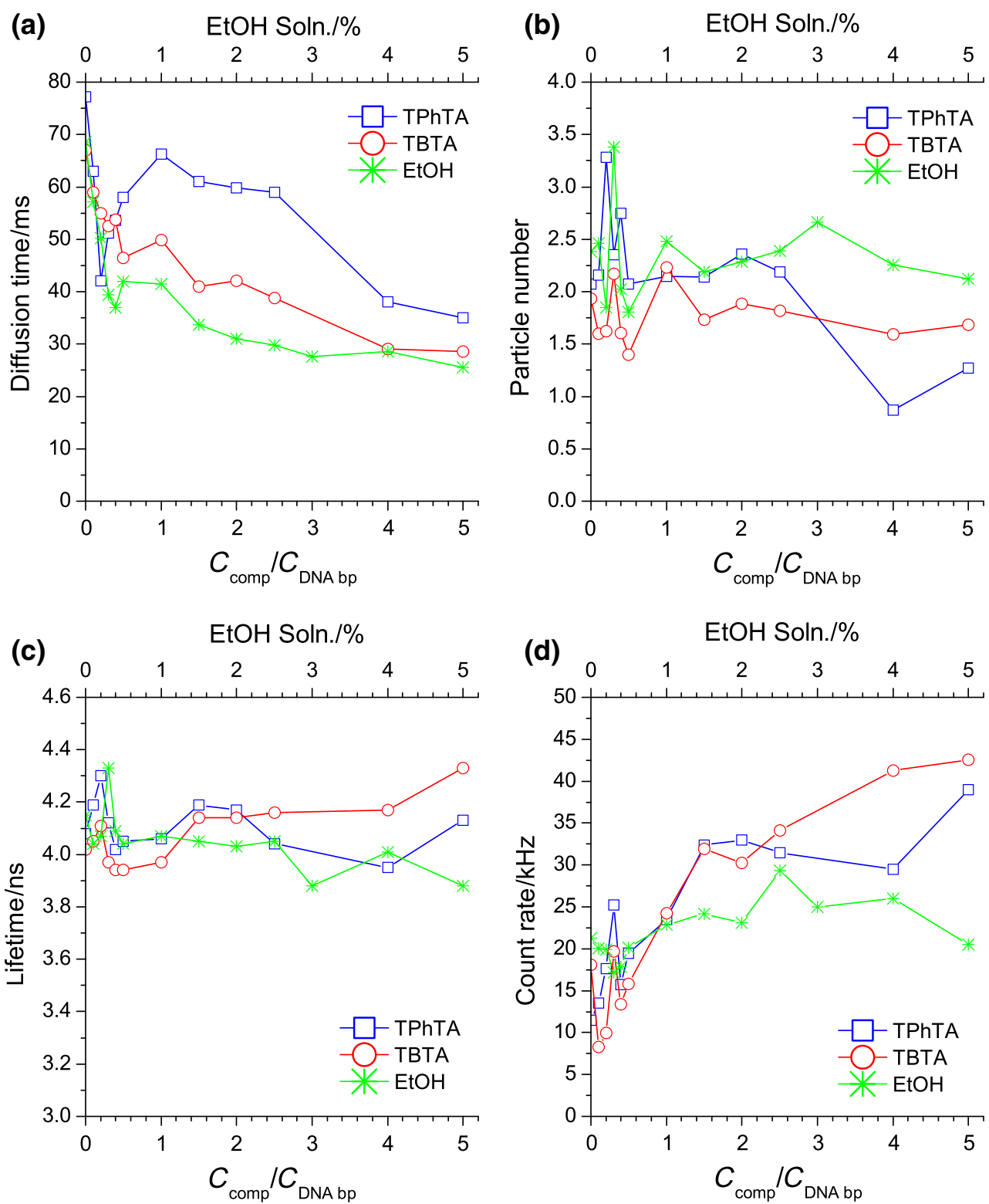

the plasmid decreased from $75 \mathrm{~ms}$ in water to $37-32 \mathrm{~ms}$ in the presence of ethanoic solutions of the TBTA and TPhTA compounds and ethanol alone. Diffusion time changes in the presence of TBTA and TPhTA occurred possibly through charge neutralization of DNA [39]; however, the presence of ethanol in both ethanoic solution TBTA and TPhTA makes this interpretation more complex. Poor nucleic acid solvent like ethanol makes interactions of DNA with its environment less favorable. Due to its semiflexible properties, the collapse of DNA is a balance between the bending stiffness and the effective self-affinity in poor solvents. Single-molecule pulling experiments have shown that the condensation forces between DNA segments in ethanol solution are much weaker than those in a solution of multivalent cations [40]. At low volume fraction of ethanol $(<20 \%)$, the size distributions of DNA in the mixture is only little changed with respect to the one in the pure aqueous solution [41]. Therefore, we may assume that TBTA and TPhTA complexes took precedence, but the presence of the ethanol has to be taken into account. Particle number (PN) values experienced fluctuation but in average remained unchanged for TBTA and ethanol alone. There is a significant decrease in the PN observed for the $C_{\mathrm{TPhTA}} / C_{\mathrm{DNA}}$ bp $<2.5$ (Fig. 6b). Compacted DNA molecules start to precipitate, which probably causes particle number to decrease. Based on the fact that PicoGreen ${ }^{\circledR}$ exhibits changes in fluorescence lifetime when bounded to folded and unfolded regions of the DNA molecule, TCSPC-FCS allows for a detailed insight into the supramolecular quality folding [24]. Plotting of the 
mean fluorescence lifetime values versus $C_{\text {compound }} /$ $C_{\text {DNA bp }}$ showed no significant changes (Fig. 6c), we infer that interactions between TBTA, TPhTA, ethanol and DNA are not able to induce its compaction. Count rate values experienced fourfold increase for TBTA and TPhTA complexes, whereas for pure ethanol, only fractional increase was observed (Fig. 6d). Therefore, no significant change in the lifetime and the particle number together with an increase in the count rate, and only twofold decrease in the final diffusion time indicated that both TBTA and TPhTA interaction resulted only in DNA fractional conformation change which did not lead to the tightly packed conformation.

\section{Summary of interaction of TTA with lipid membrane and DNA}

Our earlier studies showed structure-activity relationship in investigated compounds: They exhibited different cytostatic activities against selected cancer cell lines, and additionally, we discovered that TBTA is more hemolytically active/toxic than TPhTA (as described in our other paper which is being reviewed in preparation for publication). As it turned out investigated compounds influence the thermotropic parameters of the DPPC and DPPC/cholesterol lipid bilayer in a slightly different way: Although the temperature of the main phase transition of the DPPC remains almost unaffected, the addition of TPhTA can abolish sub- and pre-transition when added in sufficiently high concentrations. At the same time, the addition of the TBTA practically does not change the subtransition and only slightly influences the pre-transition. This leads to the conclusion that both TBTA and TPhTA interact mainly with the hydrophilic region of the lipid bilayer although the latter causes the region to be loosen thanks to which it can be penetrated with water molecules and the crystalline lipid phase $\left(L_{\mathrm{c}}\right)$ does not exist. Such difference in the behavior can be explained when the structure of both compounds is analyzed and compared. The tin atoms in TBTA complex in solid state are fivecoordinated with axial coordination sites occupied by oxygen atoms of bridging carboxylate ligand. In solutions, polymeric TBTA complex dissociate giving also trigonal bipyramidal $\mathrm{SnBu}_{3}(\mathrm{OOCR})$ (solv) complexes with $\mathrm{RCOO}$ and solvent molecule coordinated in axial positions $[12,13]$ In the presence of water in solutions, $\mathrm{H}_{2} \mathrm{O}$ is most probably coordinated to the Sn atom. The TPhTA in solid state and in solutions has pseudotetrahedral structure because phenyl groups are more sterically demanding ligands than butyl groups.

Differences of the influence on the main phase transition is the best visible when cholesterol is added to the membrane $(10 \mathrm{~mol} \%)$. Its presence increases the membrane fluidity, and addition of the investigated compounds amplifies this effect. The preliminary conclusion is that differences in toxicity of the compounds (TBTA is more toxic than TPhTA) can be caused by the differences in the way in which they affect the structure and liquidity of the membrane although differences in how they interact with the DNA also can play significant role. There is evidence that TPhTA interacted with DNA in a different mode than TBTA. The diffusion time of DNA decreases monotonically both with increased percentage of the ethanol and increasing concentration of the ethanoic solution of the TBTA compound. Diffusion time changes in the presence of TBTA and TPhTA occurred possibly through charge neutralization of DNA; however, the presence of ethanol in both ethanoic solution TBTA and TPhTA makes this interpretation more complex.

\section{Conclusions}

The aim of the present study was to compare the influence of the two tributyltin (TBTA) and triphenyltin (TPhTA) 2-[4 (dimethylamino)phenylazo]benzoates complexes which differ only in the type of the group (butyl or phenyl) on thermotropic parameters of the lipid membrane on the plasmid DNA. Generally, the toxicity of these compounds can be attributed to the changes they induce in the membrane structure (and in turn disturbance of the membrane function) or changes they cause to the DNA. The research we performed helped to explain the mechanism of the interaction of those compounds at the molecular level.

We started the physicochemical research with a simplified membrane model (one type of lipid only-DPPC, which is one of the main components of erythrocyte membranes, plus cholesterol) to check how exactly investigated compounds influence creation of different membrane phases (and thus influence phase transition).

The investigated compounds have slightly different effects on phase transitions of model lipid membranes. They cause a slight decrease in temperature of the main phase transition of DPPC and reduce its cooperativity. The changes are more pronounced for TPhTA than for TBTA, and at sufficiently high concentrations, TPhTA eliminates both the sub- and the pre-transition of DPPC. The effects are even more pronounced in the presence of cholesterol in the model membrane. Regarding the effect of those compounds on plasmid DNA - it is similar when packing order of the DNA is considered; however, analysis of the diffusion times indicates that TPhTA interacts with DNA in a different mode than TBTA.

The preliminary conclusion is that differences in toxicity of the compounds (TBTA is more toxic than TPhTA) can be caused by the differences in the way in which they affect 
the structure and liquidity of the membrane although differences in how they interact with the DNA also can play a significant role.

We believe that physicochemical research we conduct is essential for the understanding of the molecular mechanisms of interaction of investigated compounds and thus helps with designing new compounds that have potential therapeutic applications (e.g., chemotherapy). Results presented in this paper constitute only a part of the whole research we perform-further studies are conducted on more complex systems (like erythrocytes, mimetic membranes) involving different analysis methods and tools (like IR spectroscopy).

Acknowledgements The use of a DSC in the Institute of Agricultural Engineering of Wrocław University of Environmental and Life Sciences is gratefully acknowledged. Hanna Pruchnik acknowledges financial support of the statutory activities of the Department of Physics and Biophysics of the Wrocław University of Environmental and Life Sciences.

Open Access This article is distributed under the terms of the Creative Commons Attribution 4.0 International License (http://creative commons.org/licenses/by/4.0/), which permits unrestricted use, distribution, and reproduction in any medium, provided you give appropriate credit to the original author(s) and the source, provide a link to the Creative Commons license, and indicate if changes were made.

\section{References}

1. Davies AD, Gielen M, Pannell KH, Tiekink ERT, editors. Tin chemistry: fundamentals, frontiers, and applications. New York: Wiley; 2008.

2. Gielen M, Tiekink ERT. Tin compounds and their therapeutic potential. In: Gielen M, Tiekink ERT, editors. Metallotherapeutic drugs and metal-based diagnostic agents: the use of metals in medicine. Chichester: Wiley; 2005. p. 421-43.

3. Pellerito L, Nagy L. Organotin(IV) ${ }^{n+}$ complexes formed with biologically active ligands: equilibrium and structural studies, and some biological aspects. Coord Chem Rev. 2002;224:111-50.

4. Cooper C, Cagle P, Martin P, Derveer D, Jarrett WL, Holder AA. An in vitro study on the effect of synthesized tin(IV) complexes on glioblastoma, colorectal, and skin cancer cell lines. Biomed Res Clin Pract. 2016;1(1):5-13.

5. Hadjikakou SK, Hadjiliadis N. Antiproliferative and anti-tumor activity of organotin compounds. Coord Chem Rev. 2009;253:235-49.

6. Arjmand F, Parveen S, Tabassum S, Pettinari C. Organo-tin antitumor compounds: their present status in drug development and future perspectives. Inorg Chim Acta. 2014;423:26-37.

7. de Carvalho Oliveira R, Santelli RE. Occurrence and chemical speciation analysis of organotin compounds in the environment: a review. Talanta. 2010;82:9-24.

8. Gennari A, Bleumink R, Viviani B, Galli CL, Marinovich M. Identification by DNA macroarray of nur77 as a gene induced by di- $n$-butyltin dichloride: its role inorganotin-induced apoptosis. Toxicol Appl Pharmacol. 2002;181:27-31.
9. Pruchnik H, Latocha M, Zielińska A, Ułaszewski S, Pruchnik FP. Butyltin(IV) 5-sulfosalicylates: structural characterization and their cytostatic activity. Polyhedron. 2013;49:223-33.

10. Pruchnik H, Lis T, Latocha M, Zielińska A, Pruchnik FP. Novel organotin complexes containing the 2,2'-bipyridine-3,3',6,6'-tetracarboxylate. Helical supramolecular structure and cytostatic activity. J Organometal Chem. 2015;777:81-7.

11. Pruchnik H, Kral T, Poradowski D, Pawlak A, Drynda A, Obmińska-Mrukowicz B, Hof M. New cytotoxic butyltin complexes with 2-sulfobenzoic acid: molecular interaction with lipid bilayers and DNA as well as in vitro anticancer activity. Chem Biol Interact. 2016;243:107-18.

12. Pruchnik H, Pruchnik FP. Butyltin(IV) citrates and tartrates: structural characterization and their interaction with nucleotides. J Organomet Chem. 2013;729:60-7.

13. Pruchnik FP, Bańbuła M, Ciunik Z, Chojnacki H, Latocha H, Skop B, Wilczok T, Opolski A, Wietrzyk J, Nasulewicz A. Structure, properties and cytostatic activity of triorganotin (aminoaryl)carboxylates. Eur J Inorg Chem. 2002;2002:3214-21.

14. Pruchnik FP, Bańbuła M, Ciunik Z, Latocha M, Skop B, Wilczok T. Structure, properties and cytostatic activity of tributyltin aminocarboxylates. Inorg Chim Acta. 2003;356:62-88.

15. Nath M, Vats M, Roy P. Tri- and diorganotin(IV) complexes of biologically important orotic acid: synthesis, spectroscopic studies, in vitro anti-cancer, DNA fragmentation, enzyme assays and in vivo anti-inflammatory activities. Eur $\mathrm{J}$ Med Chem. 2013;59:310-21.

16. Prasad KS, Kumar LS, Chandan S, Jayalakshmi B, Revanasiddappa HD. Diorganotin(IV) complexes of biologically potent $4(3 \mathrm{H})$-quinazolinone derived Schiff bases: synthesis, spectroscopic characterization, DNA interaction studies and antimicrobial activity. Spectrochim Acta Part A. 2011;81:276-82.

17. Tariq M, Muhammad N, Sirajuddin M, Ali S, Shah NA, Khalid N, Tahir MN, Khan MR. Synthesis, spectroscopic characterization, X-ray structures, biological screenings, DNA interaction study and catalytic activity of organotin(IV) 3-(4-flourophenyl)2-methylacrylic acid derivatives. J Organomet Chem. 2013;723:79-89.

18. Casini A, Messori L, Orioli P, Gielen M, Kemmer M. Interactions of two cytotoxic organotin(IV) compounds with calf thymus DNA. J Inorg Biochem. 2001;85:297-300.

19. Sirajuddin M, Ali S, Haider A, Shah NA, Shah A, Khan MR. Synthesis, characterization, biological screenings and interaction with calf thymus DNA as well as electrochemical studies of adducts formed by azomethine [2-((3,5 dimethylphenylimino)methyl)phenol] and organotin(IV) chlorides. Polyhedron. 2012;40:19-31.

20. Girasolo MA, Tesoriere L, Casella G, Attanzio A, Capobianco ML, Sabatino P, Barone G, Rubino S, Bonsignore R. A novel compound of triphenyltin(IV) with $\mathrm{N}$-tert-butoxycarbonyl L-ornithine causes cancer cell death by inducing a p53-dependent activation of the mitochondrial pathway of apoptosis. Inorg Chim Acta. 2017;456:1-8.

21. Ohtaka H, Kawasaki Y, Kodama M. Phase transitions of highly asymmetric chain-length $N$-lignocerylsphingomyelin (C24:0-SM) bilayer. J Therm Anal Calorim. 2013;113:1593-602.

22. Pruchnik H, Kral T, Hof M. Interaction of new butyltin citrate complex with lipid model membrane and DNA. J Therm Anal Calorim. 2014;118(2):967-75.

23. Kral T, Widerak K, Langner M, Hof M. Propidium iodide and PicoGreen as dyes for the DNA fluorescence correlation spectroscopy measurements. J Fluoresc. 2005;15(2):179-83.

24. Adjimatera N, Kral T, Hof M, Blagbrough I. Lipopolyaminemediated single nanoparticle formation of calf thymus DNA analyzed by fluorescence correlation spectroscopy. Pharm Res. 2006;23:1564-73. 
25. Blume A. Biological calorimetry: membranes. Therm Acta. 1991;193:299-347.

26. Pruchnik H. Influence of cytotoxic butyltin complexes with 2-sulfobenzoic acid on the thermotropic phase behavior of lipid model membranes. J Therm Anal Calorim. 2017;127:507-14.

27. Owusu-Ware SK, Chowdhry BZ, Leharne SA, Antonijevic MD. Phase behaviour of dehydrated phosphatidylcholines. J Therm Anal Calorim. 2017;127:415-21.

28. Chatzigeorgiou P, Mourelatou A, Pollatos E, Margari D, Zogzas N, Viras K, Mavromoustakos T, Semidalas CE. Comparison of the thermal behavior and conformational changes in partially and fully hydrated dipalmitoylphosphatidylcholine system. J Therm Anal Calorim. 2018;131:887-98.

29. Wei TT, Sun HY, Deng G, Gu JY, Guo HY, Xu J, Wu RG. The interaction of paeonol with DPPC liposomes. J Therm Anal Calorim. 2018;132:685-92.

30. Gmajner D, Ulrih NP. Thermotropic phase behaviour of mixed liposomes of archaeal diether and conventional diester lipids. J Therm Anal Calorim. 2011;106:255-60.

31. Kinoshita M, Ito K, Kato S. Kinetics for the subgel phase formation in DPPC/DOPC mixed bilayers. Chem Phys Lipids. 2010;163:712-9.

32. Ruocco MJ, Shipley GG. Characterization of the sub-transition of hydrated dipalmitoylphosphatidylcholine bilayers: X-ray diffraction study. BBA. 1982;684:59-66.
33. Heimburg T. Thermal biophysics of membrane. Weinheim: Wiley-VCH Verlag; 2007.

34. McMullen TPW, Lewis RNAH, McElhaney RN. Differential scanning calorimetric study of the effect of cholesterol on the thermotropic phase behaviour a homologous series of linear saturated phosphatidylcholines. Biochemistry. 1993;32:516-22.

35. McMullen TPW, McElhaney RN. New aspects of the interaction of cholesterol with dipalmitoylphosphatidylcholine bilayers as revealed by high-sensitivity differential scanning calorimetry. Biochim Biophys Acta. 1995;1234:90-8.

36. Dumas D, Muller S, Gouin F, Baros F, Viriot M-L, Stoltz JF. Membrane fluidity and oxygen diffusion in choresterol-enriched erythrocyte membrane. Arch Biochem Biophys. 1997;341:34-9.

37. Ohvo-Rekilä H, Ramstedt B, Leppimäki P, Slotte JP. Cholesterol interaction with phospholipids in membrane. Prog Lipid Res. 2002;41:66-97.

38. Maxfield FR, Tabas I. Role of cholesterol and lipid organization in disease. Nature. 2005;438:612-21.

39. Silvestri A, Ruisi G, Barbieri R, Inorganica C. The interaction of DNA with organotin (IV) salts and complexes. Hyp Interact. 2000;126:43-6.

40. Marchetti S, Onori G, Cametti C. Ethanol-induced compaction of DNA: a viscosimetry and dynamic light scattering study. Philos Mag. 2007;87(3-5):525-34.

41. Wang Y, Ran S, Yang G. Ethanol induces condensation of single DNA molecules. Soft Matter. 2011;7:4425-34. 